\title{
Transverse craniofacial dimensions in Angle Class II, Division 1 malocclusion according to breathing mode
}

\section{Agda Rísia David Pinto Coelho(a) Orlando Tanaka(b) \\ Jucienne Salgado Ribeiro(a) Maria Ângela Naval Machado(c) Elisa Souza Camargo ${ }^{(b)}$}

(a) MSc in Orthodontics; (b) PhD, Professor of Orthodontics - Department of

Orthodontics, Pontifical Catholic University of Paraná, Curitiba, PR, Brazil.

(c) PhD, Professor of Pathology, Department of Pathology, Pontifical Catholic University of Paraná, Curitiba, PR, Brazil.

\section{Corresponding author:}

Elisa Souza Camargo

Rua Fernando Simas, 327

Curitiba - PR - Brazil

CEP: 80430-190

E-mail: elisa.camargo@pucpr.br

Received for publication on Apr 23, 2009 Accepted for publication on Nov 16, 2009

\begin{abstract}
The aim of this longitudinal study was to assess the relation between the transverse craniofacial dimensions of subjects with Class II, Division 1 malocclusion and the breathing mode presented by them. Forty Angle Class II, Division 1 malocclusion subjects of both genders participated in the study, 23 of which were predominantly nose breathers and 17 were predominantly mouth breathers. The mean age ranged from 10 years and 9 months to 14 years - Age range 1; and from 13 years and 4 months to 16 years and 6 months - Age range 2. Measurements of six transverse craniofacial dimensions were performed in P-A teleradiographs: Total Sphenoid, Total Zygomatic, Total Nasal Cavity, Total Maxilla, Total Mastoid and Total Antegonion. The transversal craniofacial dimensions were measured and compared in both groups at age ranges 1 and 2. The longitudinal assessment of age ranges 1 and 2 showed that there was no statistically significant influence of the breathing mode on the craniofacial dimensions evaluated, or on the alteration of these dimensions. Breathing mode had no influence on craniofacial development in the sample studied.
\end{abstract}

Descriptors: Mouth breathing; Cephalometry; Diagnosis.

\section{Introduction}

The clinical characteristics associated with mouth breathing include irregularities in the maxillary dental arches, proclined maxillary and mandibular incisors, tendency toward posterior crossbite and toward anterior open bite. ${ }^{1,2}$ These individuals also present the long face or adenoid facies syndrome, showing an elongation of the inferior facial height, slightly open lips, narrow maxillary arch, deep palate and Class II malocclusion..$^{3,4}$

However, these clinical signs have been queried, since not all individuals who presented them were predominantly mouth breathers, and this facial type could also be a congenital trait, not necessarily related to the breathing mode. ${ }^{5,6}$ Muscle patterns and skeletal growth are influenced only slightly by the breathing mode, since they are genetically transmitted and the facial type could be a congenital trait. ${ }^{7}$ Proffit and Fields ${ }^{8}$ (2000) have also emphasized the strong correlation between breathing mode and craniofacial dimensions.

Several studies correlating the breathing mode with the development of specific malocclusions have considered chronic mouth breathing as an etiologic factor in the alteration of facial growth and in Angle Class II, 
Division 1 malocclusion in individuals with adenoid facies. ${ }^{1,2,6,9,10}$

Leech $^{11}$ (1958) analyzed the relation between breathing mode and the development of malocclusion and concluded that predominantly mouth breathing did not seem to affect the skeletal and dental patterns. He also observed that the width of the bones was not altered in subjects with this breathing mode.

On the other hand, Linder-Aronson ${ }^{12}$ (1963) found a positive correlation between the breathing mode and craniofacial development, having observed that the facial width of mouth breathers was smaller than that of nose breathers. Moreover, Gross et al. ${ }^{13}$ (1994) found a constriction of the maxillary arches in subjects with open mouth posture.

Due to the controversial results and the few longitudinal studies found in the related literature, the aim of this study was to conduct a longitudinal assessment of the transverse craniofacial dimensions of boys and girls with Class II, Division 1 malocclusion, and assess the relation between these measurements and the breathing mode presented by them.

\section{Material and Methods}

This research project was submitted to and approved by the Research Ethics Committee, Health and Biological Science Department, Pontifical Catholic University of Paraná.

A quantitative study was conducted in a sample of 40 white Brazilian boys and girls, with Class II, Division 1 malocclusion, 23 of which were predominantly nose breathers and 17 were predominantly mouth breathers. The first age range observed was from 10 years and 9 months to 14 years (Age range 1 ), and the second was from 13 years and 4 months to 16 years and 6 months (Age range 2).

The cases were considered subjects with Class II, Division 1 malocclusion when, at maximum habitual intercuspation, they presented the first permanent mandibular molar distally located in relation to the first permanent maxillary molar, unilaterally or bilaterally (with or without subdivision), and maxillary incisors in labioversion. The subjects chosen had undergone no previous orthodontic treatment, and did not show premature loss of teeth, large den- tal cavities, or deleterious oral habits.

Anamnesis was taken, and the subjects underwent clinical extra- and intraoral exams and posteroanterior cephalometric radiography (P-A). The breathing mode was assessed by a multidisciplinary team, formed by professionals in the fields of Otolaryngology, Orthodontics and Speech and Language Pathology. ${ }^{14}$ Additionally, a questionnaire was sent to the subjects' parents.

Based on the P-A cephalometric radiographs, areas of interest were traced and the following cephalometric points (Figure 1) were marked: Sphenoid (Sph), Zygomatic (Zyg), Nasal Cavity (NC), Maxilla $(\mathrm{Mx})$, Mastoid (Ms), Antegonion (Ag), and crista galli (Nc). Except for crista galli, all points were marked at both sides, right (R) and left (L). Next, the horizontal sphenoid line (HSL) joining LSph and RSph was traced. The True Median Line (TML) was then drawn from the midpoint of the HSL to the mentum, passing through the Nc point. The following linear measurements were then obtained: To-

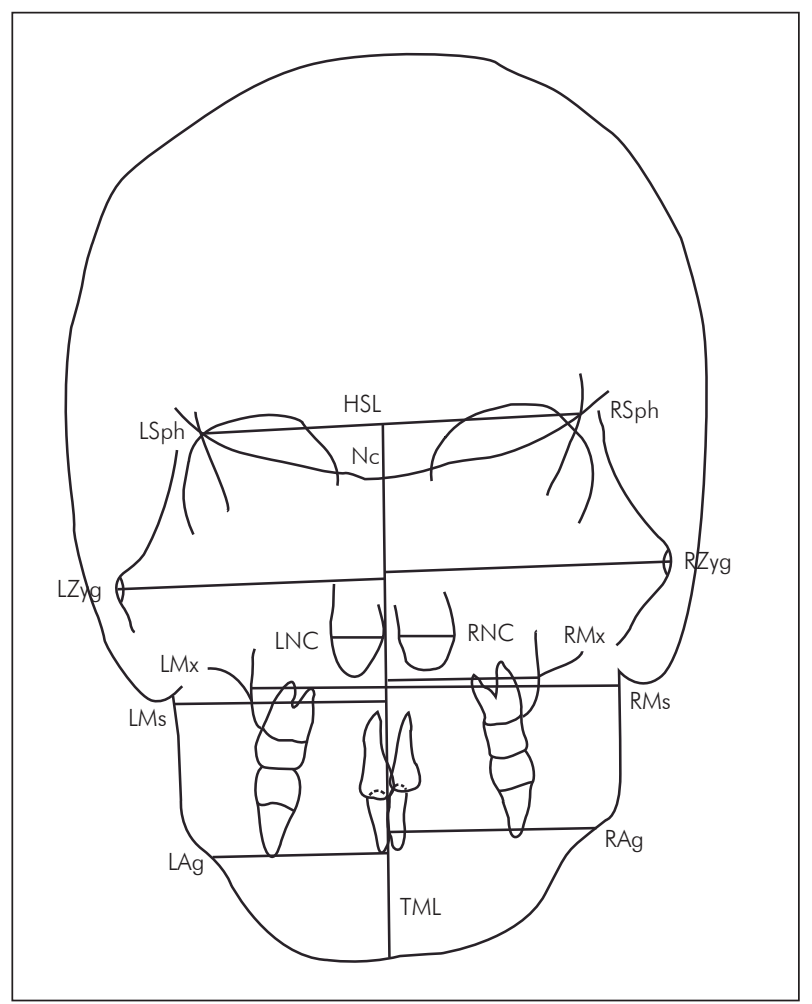

Figure 1 - Representation of the linear transverse measurements used in the study. 
tal Sphenoid (TSph), Total Zygomatic (TZyg), Total Nasal Cavity (TNC), Total Maxilla (TMx), Total Mastoid (TMs), and Total Antegonion (TAg). Each total measurement was obtained by adding the measurements of the right and left sides, which, in turn, were taken from the cephalometric point on each side, perpendicularly to the True Median Line. Each of the 6 transverse dimensions was measured for Age range 1 and Age range 2, and the behavior of these measurements between age ranges 1 and 2 was also determined, for a total of 18 measurements obtained in this study. All the procedures were performed by a single operator, with the help of a digital caliper.

The transverse craniofacial dimensions were measured and compared in the following groups: predominantly nose breathers at age ranges 1 and 2 , and predominantly mouth breathers at age ranges 1 and 2.

\section{Results}

For each sample measurement, the following data were obtained, among others: mean, confidence interval for the mean, minimum value and maximum value of the sample, standard deviation and variance coefficient. The data were stratified according to the breathing mode (predominantly nose breathers, NB, and predominantly mouth breathers, $\mathrm{MB}$ ).

The Kolmogorov-Smirnov normality test and Levene's test for equality of variances showed a normal distribution of the variables, with a confidence level over $95 \%$, and the tests indicated equality of variance among the $\mathrm{NB}$ and $\mathrm{MB}$ subjects.

The tracings and measurements performed on the P-A cephalometric radiographs were repeated and submitted to Dahlberg's error test, which confirmed the validity of the measurements obtained.

Student's $t$ test was applied to each of the 18 variables (Table 1) in order to determine whether there were relevant differences in:

- Transverse craniofacial measurements among $\mathrm{NB}$ and $\mathrm{MB}$ at Age range 1;

- transverse craniofacial measurements among NB and $\mathrm{MB}$ at Age range 2;

- alteration in the transverse craniofacial measurements from Age range 1 to Age range 2 among $\mathrm{NB}$ and $\mathrm{MB}$.
No significant difference was detected in any of the measurements, thus showing that there was no relation between breathing mode and transverse craniofacial dimensions at age ranges 1 and 2, and between breathing mode and the development of the transverse craniofacial dimensions from Age range 1 to Age range 2.

Correlation tests and Student's $t$ tests (Table 2) were also performed for paired samples, for the purpose of analyzing whether there were significant differences in the transverse craniofacial measurements between age ranges 1 and 2, for NB subjects, $\mathrm{MB}$ subjects, and for all individuals.

Alteration of all the transverse craniofacial measurements between age ranges 1 and 2 proved statistically significant. Only the TSph (Total Sphenoid) variable showed no significant alteration between age ranges 1 and 2 , in the predominantly nose breathers.

Table 1 - Means and standard deviations for the variables in both age ranges according to breathing mode, and Student's t test for independent samples.

\begin{tabular}{|c|c|c|c|c|}
\hline Variable & $\begin{array}{l}\text { Age } \\
\text { Range }\end{array}$ & Nose Breathers & $\begin{array}{l}\text { Mouth } \\
\text { Breathers }\end{array}$ & $\begin{array}{c}\mathrm{p} \\
\text { Value }\end{array}$ \\
\hline \multirow{2}{*}{ SphT } & 1 & 93.11 (4.2) & 91.17 (3.3) & 0.12 \\
\hline & 2 & 93.75 (4.32) & 93.29 (4.36) & 0.74 \\
\hline DIFSphT & & $0.63(1.92)$ & $2.12(3.36)$ & 0.09 \\
\hline \multirow{2}{*}{ ZygT } & 1 & $126.08(3.62)$ & 125 & 0.35 \\
\hline & 2 & $131.23(4.58)$ & $129.78(4.12)$ & 0.31 \\
\hline DIFZygT & & 5.15 (3.78) & $4.78(2.23)$ & 0.72 \\
\hline \multirow{2}{*}{ NCT } & 1 & 28.51 (1.99) & $27.88(2.23)$ & 0.35 \\
\hline & 2 & 29.66 (1.95) & $29.22(2.66)$ & 0.55 \\
\hline DIFNCT & & 1.15 (1.3) & 1.34 (1.03) & 0.62 \\
\hline \multirow{2}{*}{$M x T$} & 1 & $63.1 \quad(3.76)$ & $61.6 \quad(3.95)$ & 0.23 \\
\hline & 2 & 64.14 (3.38) & $63 \quad(3.9)$ & 0.33 \\
\hline DIFMxT & & $1.03(1.5)$ & $1.4 \quad(2.04)$ & 0.52 \\
\hline \multirow{2}{*}{ MsT } & 1 & $108.93(6.05)$ & $110.95(5.21)$ & 0.28 \\
\hline & 2 & 111.41 (5.98) & $113.69(6.67)$ & 0.26 \\
\hline DIFMsT & & $2.48(1.63)$ & $2.74(2.54)$ & 0.69 \\
\hline \multirow{2}{*}{$\mathrm{AgT}$} & 1 & 83.94 (4.81) & 84.77 (3.51) & 0.55 \\
\hline & 2 & $87.36(5.2)$ & $87.99(4.24)$ & 0.68 \\
\hline DIFAgT & & $3.42(1.75)$ & $3.22(2.41)$ & 0.76 \\
\hline
\end{tabular}

$\mathrm{DIF}=$ Behavior of variable between age ranges 1 and $2 .{ }^{*}$ Significant difference for $p<0.05$ 
Table 2 - Student's $t$ test for paired samples.

\begin{tabular}{|c|c|c|c|c|c|}
\hline $\begin{array}{l}\text { Breathing } \\
\text { Mode }\end{array}$ & Pair & $\begin{array}{l}\text { Average } \\
\text { Difference }\end{array}$ & D.F. & $t$ & $p$ value \\
\hline \multirow{6}{*}{$\begin{array}{c}\text { Nose } \\
\text { Breathers } \\
\text { (NB) }\end{array}$} & SphT1-SphT2 & -0.64 & 22 & -1.58 & 0.127 \\
\hline & ZygT1-ZyhT2 & -5.15 & 22 & -6.54 & $0.000^{*}$ \\
\hline & NCT1-NCT2 & -1.15 & 22 & -4.24 & $0.000^{*}$ \\
\hline & МхТ1 -MхТ2 & -1.04 & 22 & -3.31 & $0.003^{*}$ \\
\hline & MsT1-MsT2 & -2.48 & 22 & -7.3 & $0.000^{*}$ \\
\hline & AgT1-AgT2 & -3.42 & 22 & -9.37 & $0.000^{*}$ \\
\hline \multirow{6}{*}{$\begin{array}{c}\text { Mouth } \\
\text { Breathers } \\
(\mathrm{MB})\end{array}$} & SphT1-SphT2 & -2.12 & 16 & -2.6 & $0.019^{*}$ \\
\hline & ZygT1-ZyhT2 & -4.78 & 16 & -8.84 & $0.000^{*}$ \\
\hline & NCT1 -NCT2 & -1.34 & 16 & -5.36 & $0.000^{*}$ \\
\hline & MxT1-MxT2 & -1.4 & 16 & -2.81 & $0.012^{*}$ \\
\hline & MsT1 -MsT2 & -2.74 & 16 & -4.44 & $0.000^{*}$ \\
\hline & AgT1-AgT2 & -3.22 & 16 & -5.51 & $0.000^{*}$ \\
\hline \multirow{6}{*}{$\begin{array}{c}\text { Total } \\
(\mathrm{NB}+\mathrm{MB})\end{array}$} & SphT1-SphT2 & -1.26 & 39 & -2.97 & $0.005^{*}$ \\
\hline & ZygT1-ZyhT2 & -4.99 & 39 & -9.92 & $0.000^{*}$ \\
\hline & NCT1 -NCT2 & -1.23 & 39 & -6.58 & $0.000^{*}$ \\
\hline & MxТ1-MxT2 & -1.19 & 39 & -4.33 & $0.000^{*}$ \\
\hline & MsT1-MsT2 & -2.59 & 39 & -8.03 & $0.000^{*}$ \\
\hline & AgT1-AgT2 & -3.33 & 39 & -10.39 & $0.000^{*}$ \\
\hline
\end{tabular}

D.F. $=$ Degree of freedom; $1=$ Age range $1 ; 2=$ Age range $2 .{ }^{*}$ Significant difference for $p<0.05$.

\section{Discussion}

The main goal of orthodontics is to achieve a balance between esthetics and functionality of the dentocraniofacial complex by means of a precise diagnosis and correction of any anomalies in this complex.

In addition to being commonly adopted for evaluating symmetries, the P-A teleradiographs used in this research allow an analysis of the transverse craniofacial dimensions. ${ }^{15-18}$

The research described in this article pointed out that growth of transverse craniofacial dimensions continues even after puberty; this was also observed by Athanasiou et al. ${ }^{16}$ (1992) and by Lux et al. ${ }^{18}$ (2004). An increase in these measurements in the sample studied was detected in a time period of two and a half years, starting at the age of 10 years and 9 months up to age 14 . The exception noted referred to an increase in the Total Sphenoid measurement (TSph), which showed no statistically significant difference in individuals who were predominantly nose breathers. Therefore, bone development in this region did not occur in a way similar to the increase in the other measurements analyzed. This was probably associated with the fact that the sphenoid bone is located in the skull, where growth ceases at an early age when compared with facial growth..$^{8,18}$

The study described in this paper did not identify a correlation between the transverse craniofacial dimensions and the breathing mode in individuals with Class II, Division 1 malocclusion (Table 1). These results indicate that the transverse craniofacial measurements are determined mainly by genetic factors, and are not influenced by the breathing mode. In this respect, Brodie ${ }^{19}$ (1941) stated that the morphogenetic pattern of the head is established when the individual is approximately 3 months old, and that facial growth follows a consistent vector and does not register individual variations. For Gwynne-Evans and Ballard (1958), muscle patterns and skeletal growth are genetically transmitted and are influenced only slightly by the breathing mode; there is no morphological type associated with mouth breathing. The high relation of heredity in the craniofacial dimensions and low relation of heredity in the variation of dental arches have already been established. However, the impact of these on the etiologic factors of malocclusions, which present dental as well as skeletal components, is still unknown. ${ }^{8}$

As regards identifying the breathing mode, there is no consensus about characterizing it as predominantly mouth breathing or nose breathing. Several diagnostic methods have been used. In this study, a multidisciplinary approach was chosen because of the confidence level and precision. ${ }^{14}$

It was not the aim of the present study to establish a causal relationship between the breathing mode and malocclusion, but, rather, to analyze the influence of the breathing mode on the development of transverse craniofacial measurements in individuals with Class II, Division 1 malocclusion. As was shown, no such influence was detected; however, mouth breathing cannot be considered the only etiologic factor of Class II, Division 1 malocclusion, since the sample in this research included 23 individuals with this malocclusion, who were predominantly nose breathers. Other studies ${ }^{1,9,10}$ have tried to establish a causal 
relationship between the breathing mode and the development of malocclusions. Hawkins ${ }^{9}$ (1969) observed that Class II, Division 1 malocclusions with adenoid facies could be attributed to predominantly mouth breathing, which would produce muscular imbalance, resulting in the narrowing of the maxillary arch, protrusion of the maxillary anterior teeth, shortening of the upper lip and lower lip in a hypotonic condition. Linder-Aronson ${ }^{1}$ (1979) associated characteristics such as narrow maxilla, proclined maxillary and mandibular incisors, and a tendency toward posterior cross bite and anterior open bite with mouth breathing. Melsen et al. ${ }^{10}$ (1987) noticed that children who were mouth breathers showed a greater incidence of distocclusion, anterior open bite, posterior cross bite and crowding.

Studies with objectives similar to those set for this research have endeavored to identify whether there was a correlation between the breathing mode and the development of dentocraniofacial dimensions. The results of the current research agree with the results found by Leech ${ }^{11}$ (1958), who analyzed boys and girls with ages between 2 and 13 years, 56\% with Angle Class I, 36\% with Class II, and 8\% with Class III, and concluded that mouth breathing seemed to affect neither the skeletal and dental patterns nor the bone width. According to Shaughnessy ${ }^{20}$ (1983), although discussed at length in the literature, the long face or adenoid face syndrome does not characterize a pathognomonic sign of mouth breathing, and the alterations attributed to mouth breathing would indeed depend on individual adaptation of the muscular function.

On the other hand, the results obtained by the research described in this paper differ from those obtained by Linder-Aronson ${ }^{12}$ (1963), who compared the differences between nose breathers and mouth breathers in a 2-year longitudinal study that began with subjects who were 10 years old. In addition to the breathing mode, the presence of labial sealing at

\section{References}

1. Linder-Aronson S. Respiratory function in relation to facial morphology and the dentition. Br J Orthod. 1979 Apr;6(2):5971. rest was assessed and complementary exams, such as P-A cephalometric radiographs, were performed, with measurements of the maximum height of the face and nose. It was observed that children who were mouth breathers had a significantly larger facial index than children who were nose breathers, that is, smaller facial width. Gross et al. ${ }^{13}$ (1994) performed a longitudinal assessment in 348 children in order to establish the influence of an open mouth in dentofacial development. They observed that children with an open mouth posture showed a greater constriction of the maxillary arches than children with labial sealing. However, they did not perform measurements in the skeletal structures, and this has made it impossible to compare their study with the present study.

From the results presented in this paper, one may conclude with a high level of confidence that the breathing mode has no influence on the transverse craniofacial measurements in individuals with Angle Class II, Division 1, malocclusion between the ages of 10 years and 9 months and 14 years (Age range 1 ), and between the ages of 13 years and 4 months and 16 years and 6 months (Age range 2). It was also observed that there was a significant development of the transverse dimensions of the craniofacial complex between the two age ranges analyzed, considering the predominantly nose breathers and the predominantly mouth breathers that comprised the sample, except for the Total Sphenoid measurement (TSph) in predominantly nose breathers.

Further research should be conducted with larger samples, stratified according to gender and type of occlusion, facial pattern and with longitudinal analyses ranging from childhood to adult life.

\section{Conclusions}

This study concluded that the breathing mode had no influence on the transverse craniofacial development.

2. Hesby RM, Marshall SD, Dawson DV, Southard KA, Casko JS, Franciscus RG, et al. Transverse skeletal and dentoalveolar 
changes during growth. Am J Orthod Dentofacial Orthop. 2006 Dec;130(6):721-31.

3. Vig KW. Nasal obstruction and facial growth: the strength of evidence for clinical assumptions. Am J Orthod Dentofac Orthop. 1998 Jun;113(6):603-11.

4. Peltomäki T. The effect of mode of breathing on craniofacial growth -- revisited. Eur J Orthod. 2007 Oct; 29(5):426-9.

5. O'Ryan FS, Gallagher DM, LaBanc JP, Epker BN. The relation between nasorespiratory function and dentofacial morphology: a review. Am J Orthod. 1982 Nov;82(5):403-10.

6. Lessa FC, Enoki C, Feres MF, Valera FC, Lima WT, Matsumoto MA. Breathing mode influence in craniofacial development. Braz J Otorhinolaryngol. 2005 Mar-Apr;71(2):156-60. Epub 2005 Aug 2.

7. Gwynne-Evans E, Ballard CF. The mouth breather. Am J Orthod. 1958 Jul;44(7):559.

8. Proffit W, Fields. H. Contemporary Orthodontics. $3^{\text {rd }}$ ed. St. Louis: Mosby Company; 2000.

9. Hawkins AC. Mouth breathing and its relationship to malocclusion and facial abnormalities. N M Dent J. 1969 May;20(1):18-21.

10. Melsen B, Attina L, Santuari M, Attina A. Relationships between swallowing pattern, mode of respiration, and development of malocclusion. Angle Orthod. 1987 Apr;57(2):11320.

11. Leech HL. A clinical analysis of orofacial morphology and behavior of 500 patients attending an upper respiratory research clinic. Dent Pract. 1958 Dec;9(4):57-68.

12. Linder-Aronson S. Dimensions of face and palate in nose breathers and in habitual mouth breathers. Odontol Revy. 1963;14(3):187-99.
13. Gross AG, Kellum GD, Franz D, Michas K, Walker M, Foster $\mathrm{M}$, et al. A longitudinal evaluation of open mouth posture and maxillary arch width in children. Angle Orthod 1994;64(6):419-24.

14. Wieler WJ, Barros AM, Barros LA, Camargo ES, Ignácio SA, Maruo H, Tanaka OM. A combined protocol to aid diagnosis of breathing mode. Rev de Clin Pesq Odontol. 2007 MayAug:3(2):101-14.

15. Emsli RD, Massler M, Zwemer JD. Mouth breathing: Etiology and effects: a review. J Am Dent Assoc. 1952 May;44(5):50621.

16. Athanasiou AE, Droschl H, Bosch C. Data and patterns of transverse dentofacial structure of 6-to 15-year-old children: a posteroanterior cephalometric study. Am J Orthod Dentofacial Orthop. 1992 May; 101(5):465-71.

17. Snodell SF, Nanda RS, Currier GF. A longitudinal cephalometric study of transverse and vertical craniofacial growth. Am J Orthod Dentofacial Orthop. 1993 Nov;104(5):471-83.

18. Lux CJ, Conradt C, Burden D, Komposch G. Transverse development of the craniofacial skeleton and dentition between 7 and 15 years of age - a longitudinal postero-anterior cephalometric study. Eur J Orthod. 2004 Feb;26(1):31-42.

19. Brodie AG. On the growth pattern of the human head from the third month to the eighth year of life. Am J Anat 1941;68(2):209-62.

20. Shaughnessy TG. The relationship between upper airway obstruction and craniofacial growth. J Mich Dent Assoc. 1983 Sep;65(9):431-3. 